\title{
Efficacy Of Orientation Classes In Local Languages As A Part Of Foundation Course In New Competency Based Medical Education Curriculum.
}

\author{
Dr. Sudipa Biswas *, Dr. Chandrasekhar Mahakalkar ${ }^{* *}$, Dr. Soumya Chakraborty ${ }^{* *}$ \\ * Department of Anatomy,ESIC Medical College, Joka, Kolkata. \\ ** Department of General Surgery, NMC Sawangi, Meghe. Wardha, Maharashtra. \\ *** Department of Anatomy, ESIC Medical College, Bihta, Bihar. \\ DOI: 10.29322/IJSRP.11.07.2021.p11564 \\ http://dx.doi.org/10.29322/IJSRP.11.07.2021.p11564
}

\begin{abstract}
Learning something in one language and application of the acquired knowledge in some other language often becomes very troublesome. All the books and instructions are in English in teaching Medical sciences, but the students have to deal with the patients' problem in local languages. Communication skill depends largely on the knowledge of the language we use, and obviously the outcome would be better if both the patients and students(would be doctor) are communicating in the same language. Medical Council of India, has started with the incorporation of lots of different topics in Foundation course $\left(1^{\text {st }}\right.$ month of Medical curriculum) along with local language with the idea for improvement of communication skill and attitude of students towards their patients. Our topic of discussion is effect of teaching local language during the Foundation course and to note whether the students use the local language during early clinical exposure or not.

The Bengali speaking students were mentors (35) and other students (65)were participants. Mentors were asked to teach two Bengali words per day to the participants during foundation course. After one month of four early clinical exposures, the students were asked to give their idea about the project. We have taken pre and post scoring for the same questionnaire before and after the completion of the project. Data collected were analysed for statistical evaluation.The students understand local language, Bengali more(15.38\%) after the whole session, they communicated(talked) more with people in Bengali (23.07\%), they were able to understand the patient's problem in Bengali (29.23\% more) and communicated accordingly. It was showing that with the idea of local language students were more confident than before and that can positively affect health care delivery system and doctor patient relationship.
\end{abstract}

Index Terms- Foundation Course, Competency Based Medical Education, Curriculum., Local Language, Orientation Classes,

\section{INTRODUCTION}

Teaching local language as a part of foundation course in new competency based medical education curriculum has been started since the academic year(2019-2020) in India. The project started with the $1^{\text {st }}$ year Medical students. It is known to all that when we are asked to tell or describe something, then we always choose a language that is easy for us to express our thoughts and emotions. Though the students are taught medicine in English but the patients may be only knowing their mother tongue(local language) to express their problem. In a study done by Mirza DM(1) and Hashim MJ, it was shown how communication skills training in English alone can leave Arab medical students non confident with patient communication in their native language [1]. In India we have so many local languages(26, official local languages) apart from Hindi and English, that it often becomes very difficult for the students to understand the problem of patients expressed in their local languages. In another study by Drouin J et al, it was shown that educating future physicians for a minority population can help the doctor patient relationship[2]. There are many studies done to support the use of local languages for better patient interaction with the doctor[3,4,5]. Maria Shoaib et al, in their study also have proved that language barrier between doctor and patient can be a compromising factor for quality of patient care[6].

A short pilot study was conducted before the starting of the study with a group of 5 students( 3 Non Bengali speaking students and 2 Bengali speaking students of the $1^{\text {st }}$ year MBBS batch 20192020.

This study was done to observe whether teaching local languages as a part of Foundation course in new competency based medical education (CBME) curriculum [7]is effective to increase the orientation of students for early clinical exposure or not.

\section{RESEARCH DETAILS}

\section{Aims:}

To note the change in orientation of students, taught in local languages as a part of foundation course in new competency based medical education curriculum for early clinical exposure.

Objectives:

1. To sensitise the students about competency based curriculum.

2. To sensitise the teachers about competency based curriculum. 
3. To note students' idea about the local languages before the starting of foundation course.

4. To note students' idea about the local languages at the end of foundation course.

5. To note the use of local languages by the students during early clinical exposure.

6. To collate the feedback of students about the change in orientation after getting some idea about the local languages during foundation course and its use during early clinical exposure.

\section{Material and Methods:}

Study design: Observational study

Study duration: The foundation course(1 month ) and $1^{\text {st }}$ month of new CBME curriculum (therefore, total 2 months)

Study participants: Students of $1^{\text {st }}$ year MBBS.(2019-2020

batch)

Inclusion criteria: All the students, willing to participate in the study.

Exclusion criteria: Students from previous batch.

Sample size: Approximately $100,1^{\text {st }}$ MBBS students(65 Non

Bengali speaking students were participants and 35 Bengali

speaking students were mentors).

Sampling method: All the students willing to participate in the study were taken in to consideration for collecting data.

Ethical consideration: IEC approval was taken.

\section{STUDIES AND FINDINGS}

\section{Observation \& Results:}

4 (four) students were absent from mentor group; so the study was done with 31 mentors and 65 participants(total-96 students).The whole session of two months were utilised by the $1^{\text {st }}$ year students to learn local language(Bengali) for communication with patients during early clinical exposure sessions. The participants showed interest and they interacted with the patients mainly under the supervision of their mentors in local language as far as possible. The whole session was supervised by the faculty.

Following are the data received after the session and the Table I, showed how the session helped the students to understand the patients' problem in local language. There were significant changes in patient interaction after the local language classes, as answered by the students for the first 6 (six) questions in questionnaire(annexure). These questions were all related to understanding and communicating in local language (Bengali). From question number 7 onward the students were asked regarding their communication in Hindi(National language) also._In Table-I,q1 'q2...q13...denotes the question numbers as shown in questionnaire (annexure). q_Pre and post denotes the values of pre test and post test respectively. All the results for $95 \%$ confidence interval showed statistical significant $(\mathbf{P}<\mathbf{0 . 0 5})$ change in result for pre vs post-tests. It signifies that the session with local language significantly increases the understanding and communication skill of the students in terms of dealing with the patients. 6 point Likert Scale was used to take the data input.

In Graph -I the representation of the pre vs. post-test scoring is shown .In this graph, Series 1---Response in pre-test, Series 2--response in post-test and 1 to 13 on the left hand side of the graph represents the question numbers as per the questionnaire box(annexure). In this graph we can see clearly that for $1^{\text {st }} 6$ questions, there were significant changes in post score. Like, for the $1^{\text {st }}$ question, (Do you understand local language, Bengali ?) pre score was $20 \%$ and post score was $35.38 \%$. Similarly there are changes from 33.85 to $56.92 \%$ in $2^{\text {nd }}$ question ( Can you freely communicate(talk) with people in Bengali?), 38.46 to $50.77 \%$ in $3^{\text {rd }}$ question (Will you be able to introduce yourself to a patient in Bengali? ),40 to $64.62 \%$ in $4^{\text {th }}$ question (Will you be able to ask the patient his/her name in Bengali? ), 44.62 to $75.38 \%$ in $5^{\text {th }}$ question (Will you be able to ask the patient his/her problem in Bengali? ), 58.46 to $87.69 \%$ in $6^{\text {th }}$ question (Will you be able to understand the patient's problem in Bengali ? ). For the next 7 questions analysis showed varied result and they are related to knowledge of Hindi in students.

From the feedback given by the students regarding the orientation classes in local language as a part of foundation course in new CBME curriculum the chart (Table-II) was made. 
$100 \%$ students agreed that, the need for knowing the local language, the ways of knowing the local language and improving it were made clear in the session. 100\% students got motivated to know about the local language after the session. $95.2 \%$ students opined that the session for local language was useful for interacting well with patients and relatives. With reference to Graph II and III, $96.8 \%$ agreed that there are possible ways to improve their local language skill(talking) in future and majority (90.3\%) of students agreed to practice local language skill with their peer group. Except for $4.8 \%$ students, $93.5 \%$ students accepted the session was beneficial not only for improving doctor patient relationship but also for other purposes. 44 students answered the open question in feedback form(Annexure) as Graph IV. From Table-II, and Graph II,III,IV it is quite evident that the students understood the role of knowing local language very well as also the importance of it to improve the doctor-patient relationship.

\section{IV.DISCUSSION:}

The whole study was planned according to the recommendation of MCI for the Foundation course. In "Medical Education in India: Current challenges and the way forward" Anjali Solanki et al, shown the right pathway for the changes needed in Medical education system[8]. As anticipated the study was taken up by the whole batch of students very enthusiastically. Mentor students took great initiative to teach Bengali to the group participants. They have successfully made the participants talk and communicate with the patients in Bengali. We tried to involve not only the non Bengali students but also the Bengali speaking students in this project. It was a challenge to make the non Bengali students motivate to learn Bengali as 65 students out of 100 were from outside West Bengal. Their languages were, Assamese, Oriya, Tamil, Telugu, Kannada, Rajasthani, Bhojpuri, Bihari, Malayalam, Marathi etc. As the students understood the importance of knowing local language they learned Bengali very quickly. They used the knowledge during their early clinical exposure classes. In the result it is being reflected very well. They understand local language, Bengali more( $15.38 \%$ ) after the whole session, they communicated(talked) more with people in Bengali (23.07\%), they were able to introduce themselves to a patient in Bengali more confidently than before $(12.31 \%)$, they were able to ask the patient his/her name in Bengali( $24.62 \%$ more than before), they were able to ask the patient his/her problem in Bengali ( $30.76 \%$ more), and they were able to understand the patient's problem in Bengali ( $29.23 \%$ more) and communicated accordingly. As compared with the study done by Burbano O'Leary SC[9] our study also showed that with the idea of local language students were more confident than before. Same type of studies were done by Monroe AD and Shirazian T [10] \& Timmins CL[11] to prove that linguistic barriers can always affect health care delivery system and doctor patient relationship.

Sample size was not large(100) and the duration was only two months for this study to be completed, so any concrete inference cannot be drawn from this study. For getting better idea of knowing importance of local language we can extend the study for the next whole year or more. Therefore, this study will continue in future for evaluating the impact regarding understanding the role of local language in health care delivery system.

\section{V.CONCLUSION:}

Sensitization of the students and teachers about competency based curriculum was done successfully with role play , video and lecture classes. Students' idea about the local languages before and after the starting of foundation course was taken with same questionnaire that showed positive influence and statistically significant results. The observation check list was used to note the use of local languages by the students during early clinical exposure and it was found that students were using local language successfully. They were able to ask the patient his/her problem in Bengali, 30.76\% more than before, and they were able to understand the patient's problem in Bengali $29.23 \%$ more than before. There was significant increase in use of local language and more interactions were made during early clinical exposure classes than before. After getting the feedback of students about the change in orientation (after getting some idea about the local language during foundation course and its use during early clinical exposure ) we draw an impact pathway that showed how they understood the ways and need for knowing the local language (100\%), and improving in the class $(100 \%)$. They also understood that local language class was useful for interacting well with patients and relatives (95.2\% cases). After the session $100 \%$ students got motivated to know the local language more than before and $96.8 \%$ understood that there were possible ways to improve local language skill(communication) in future . $90.3 \%$ agreed to go on practicing the local language skill with classmates and seniors too.

As per the enthusiasm shown by the students (both the participants and mentors) it was quite obvious that the project was successful to imbibe the idea among the students about the importance of knowing local language during Foundation course in 1st year MBBS course.

The data analysis showed positive outcome i,e, there were improvement in students attitude and communication skill regarding patient interaction after the orientation classes for local language(Bengali).

Therefore, we can conclude that the orientation classes in local language for Bengali as a part of foundation course in new competency based medical education curriculum was effective in understanding the patients' problem thereby improving doctor patient relationship. 


\section{VI.ACKNOWLEDGEMENTS}

I like to acknowledge, Dr. Ashish Kumar Yadav ,Assistant Professor, Community Medicine, ESIC Medical College ,Joka, Kolkata, for his support and help for statistical analysis. I would also like to thank all the teaching and nonteaching staffs of Anatomy Department, ESIC Medical College ,Joka, Kolkata, who supported me to complete the project. I am thankful to all the students of $1^{\text {st }}$ year MBBS 2019-2020 batch of ESIC Medical College ,Joka, Kolkata, who have participated in the project and took interest in learning Bengali with great enthusiasm.

\section{VII.REFERENCES}

1. Mirza DM(1), Hashim MJ. Communication skills training in English alone can leave Arab medical students unconfident with patient communication in their native language. Education for health (Abingdon, England). 2010 August;23(2):450.

2. J Drouin, P Jean. Educating future physicians for a minority population: a French-language stream at the University of Ottawa. Academic Medicine. 2002;77(3):217-21.

3. Antic Z. Analysis of student's errors in English for medical purposes. Scientific Journal of Faculty Medicine Nis. 2010;27(3):15963.

4. Yolanda Partida. Language Barriers and the Patient Encounter. American Medical Association Journal of Ethics. Aug 2007

5. Lalit Narayan. Department of Anthropology, 209 Maxwell Hall, Syracuse, NY 13244, USA; 1dnaraya@syr.edu. The National Medical Journal of India. VOL. 26, NO. 4, 2013.

6. Maria Shoaib, Syed Ahsanuddin Ahmed, Syed Uzair Mahmood, Muhammad Yusuf Hafiz.

Doctor patient language barrier - compromising on quality care. Journal of Ayub Medical College, Abbottabad-

Pakisthan.2016.Vol 28,no 2.

7.UG Curriculum | MCI India https://www.mciindia.org/CMS/information-desk/for-colleges/ug-curriculum 8. Anjali Solanki, Surender Kashyap. Medical education in India: Current challenges and the way forward. Medical Teacher . 2014 Dec;36(12):1027-31. doi:10.3109/0142159X.2014.927574. Epub 2014 Sep 5.

9. Burbano O’Leary SC, Federico S, Hampers LC. The truth about language barriers: One residency program's experience. Pediatrics 2003;111(5 Pt 1):e569-73.

10. Monroe AD, Shirazian T. Challenging linguistic barriers to health care: students as medical interpreters. Academic Medicine. 2004 February;79(2):118-122.

11. Timmins CL. The impact of language barriers on the health care of Latinos in the United States: a review of the literature and guidelines for practice. Journal of Midwifery \& Women's Health. 2002 March-April;47(2):80-96. 


\section{VIII.AUTHORS}

$1^{\text {st }}$ and corresponding Author:

Dr. Sudipa Biswas(MD in Anatomy)

Professor and head of the Department of Anatomy

ESIC Medical College, Joka, Kolkata, India.

e-mail: sudipabiswas41@gmail.com.

Phone-9836011390

Second author: Dr. Chandrasekhar Mahakalkar,(MS in General Surgery)

Professor,

Department of General Surgery,

Medical Superintendent AVBRH.

JNMC Sawangi, Meghe.

Wardha, Maharashtra, India.

e-mail:cmahakalkar@rediffmail.com

Third author: Dr. Soumya Chakraborty(MS in Anatomy)

Professor \& Principal,

ESIC Medical College, Bihta, Bihar

e-mail:soumtuab@gmail.com 


\section{V.ANNEXURE}

Table- I: Comparison of pre and post test scores,

(done by $t$ test for the $1^{\text {st }} \operatorname{six}(6)$ questions.)

\begin{tabular}{|c|c|c|c|c|}
\hline Variables & Mean & \multicolumn{2}{|c|}{ [95\% Confidential Interval } & $P$ value \\
\hline q1_pre & 2.4 & 2.064113 & 2.735887 & 0.0000 \\
\hline q1_pst & 3.569231 & 3.165459 & 3.973002 & \\
\hline q2_pre & 2.215385 & 1.910355 & 2.520414 & 0.0001 \\
\hline q2_pst & 3.153846 & 2.797366 & 3.510326 & \\
\hline q3_pre & 2.8 & 2.422682 & 3.177318 & 0.0010 \\
\hline q3_pst & 3.661538 & 3.315863 & 4.007214 & \\
\hline q4_pre & 3.461538 & 3.043507 & $\mathbf{3 . 8 7 9 5 7}$ & 0.0000 \\
\hline
\end{tabular}




\begin{tabular}{|c|c|c|c|c|}
\hline q4_pst & 4.569231 & 4.253455 & 4.885006 & \\
\hline q5_pre & 3 & 2.575313 & 3.424687 & 0.0009 \\
\hline q5_pst & 3.938462 & 3.585644 & 4.291279 & \\
\hline q6_pre & 2.784615 & 2.361077 & 3.208154 & 0.0248 \\
\hline q6_pst & 3.446154 & 3.047014 & 3.845293 & \\
\hline q7_pre & 5.076923 & 4.795396 & 5.35845 & For the \\
\hline q7_pst & 5.123077 & 4.80567 & 5.440484 & next 7 \\
\hline q8_pre & 5.169231 & 4.8768 & 5.461661 & questions \\
\hline q8_pst & 4.784615 & 4.401514 & 5.167717 & comparison \\
\hline q9_pre & 5.261538 & 5.008855 & 5.514222 & was not \\
\hline q9_pst & 4.984615 & 4.627432 & 5.341798 & done as \\
\hline q10_pre & 5.507692 & 5.326435 & 5.68895 & these \\
\hline q10_pst & 5.292308 & 4.971248 & 5.613367 & questions \\
\hline q11_pre & 5.230769 & 4.980021 & 5.481518 & were for \\
\hline q11_pst & 4.923077 & 4.571811 & 5.274343 & Hindi. \\
\hline q12_pre & 5.261538 & 5.028611 & 5.494466 & \\
\hline q12_pst & 4.892308 & 4.538821 & 5.245794 & \\
\hline q13_pre & 5.246154 & 5.022669 & 5.469639 & \\
\hline q13_pst & 5.030769 & 4.64898 & 5.412559 & \\
\hline
\end{tabular}


Table-II :Role of Local language_-Bengali in orientation of medical students.

\begin{tabular}{|c|c|c|c|c|}
\hline $\begin{array}{l}\text { SL.N } \\
\mathbf{O}\end{array}$ & STATEMENT & Yes \% & No $\%$ & $\begin{array}{l}\text { May be } \\
\%\end{array}$ \\
\hline 1 & $\begin{array}{l}\text { The need for knowing the local language is made } \\
\text { clear in the class. }\end{array}$ & $100 \%$ & & \\
\hline 2 & $\begin{array}{l}\text { Ways of knowing the local languages and } \\
\text { improving it are made clear in the class. }\end{array}$ & $100 \%$ & & \\
\hline 3 & $\begin{array}{l}\text { Local language class is useful for interacting well } \\
\text { with patients and relatives. }\end{array}$ & $95.2 \%$ & $4.8 \%$ & \\
\hline 4 & $\begin{array}{l}\text { After the class I got motivated to know the local } \\
\text { language more than before. }\end{array}$ & $100 \%$ & & \\
\hline 5 & $\begin{array}{l}\text { There are possible ways to improve my local } \\
\text { language skill(talking) in future. }\end{array}$ & $96.8 \%$ & $3.2 \%$ & \\
\hline 6 & $\begin{array}{l}\text { Local language class was beneficial not only for } \\
\text { improving doctor patient relation but also for } \\
\text { other purposes }\end{array}$ & $93.5 \%$ & $4.8 \%$ & $1.6 \%$ \\
\hline 7 & $\begin{array}{l}\text { Will you go on practicing the local language skill } \\
\text { with your classmates and seniors? }\end{array}$ & 90.3 & & $9.7 \%$ \\
\hline
\end{tabular}

Graph-I: Comparison of changes in pre vs post test 


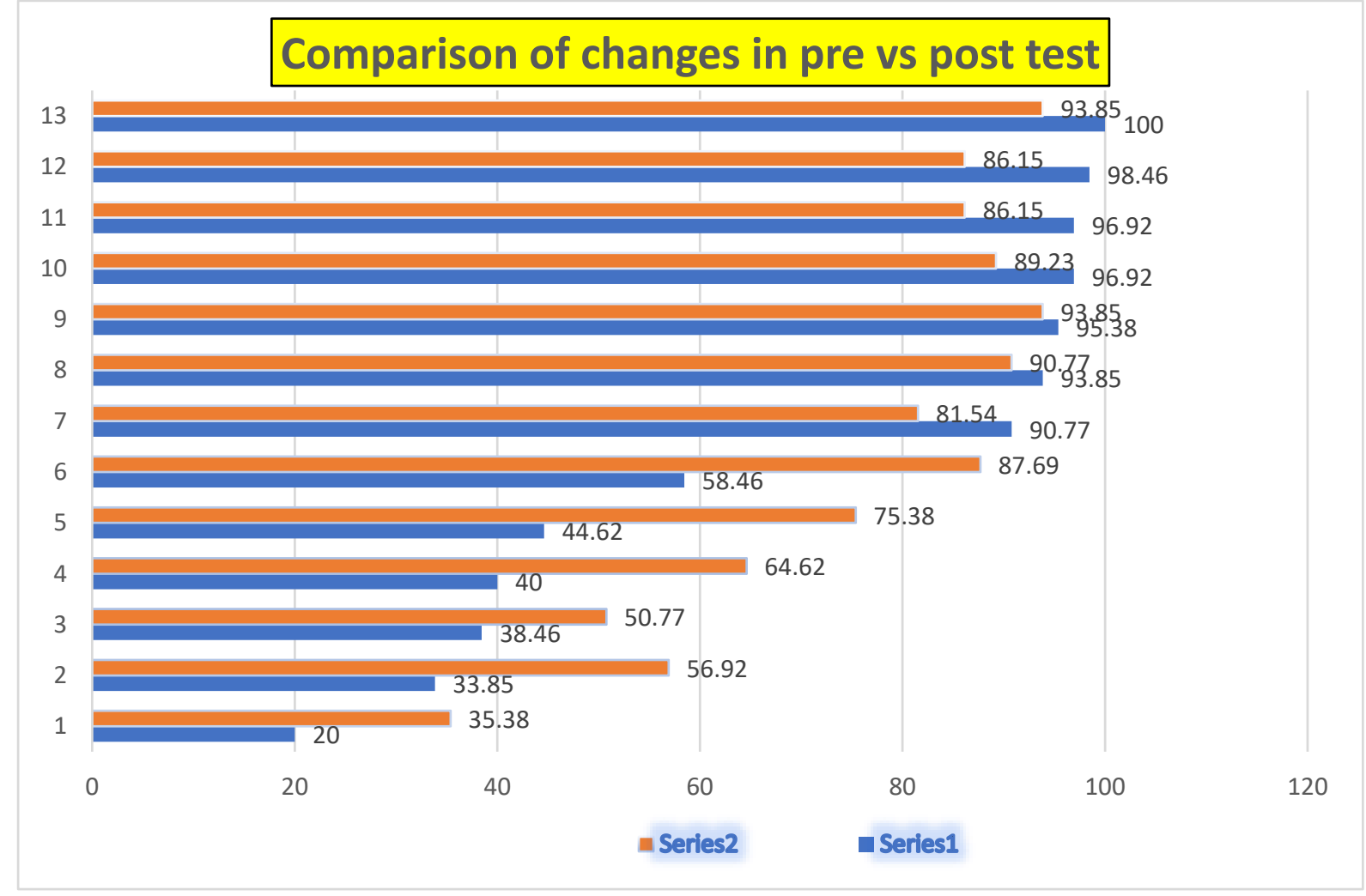

Graph-II: Usefulness of local language class for interaction with patients and relatives.

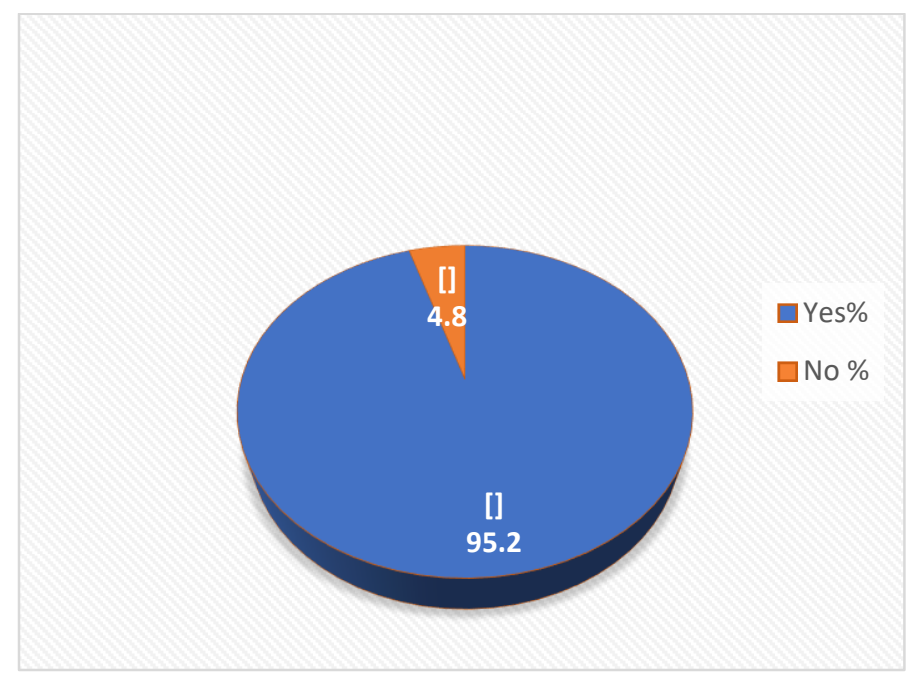

Graph III: Usefulness of local language class to improve doctor patient relationship and other purposes . 


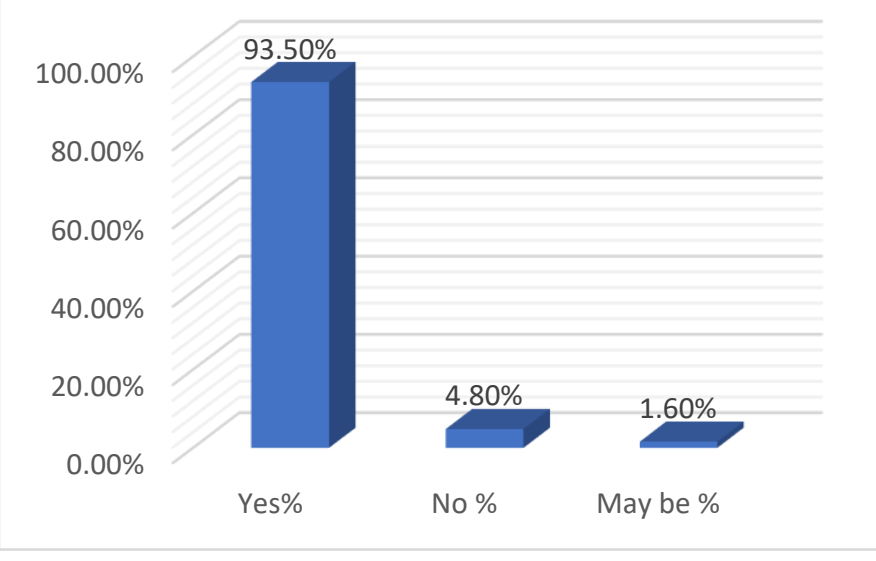

Graph IV: Ideas of the students regarding usefulness of knowing local language.

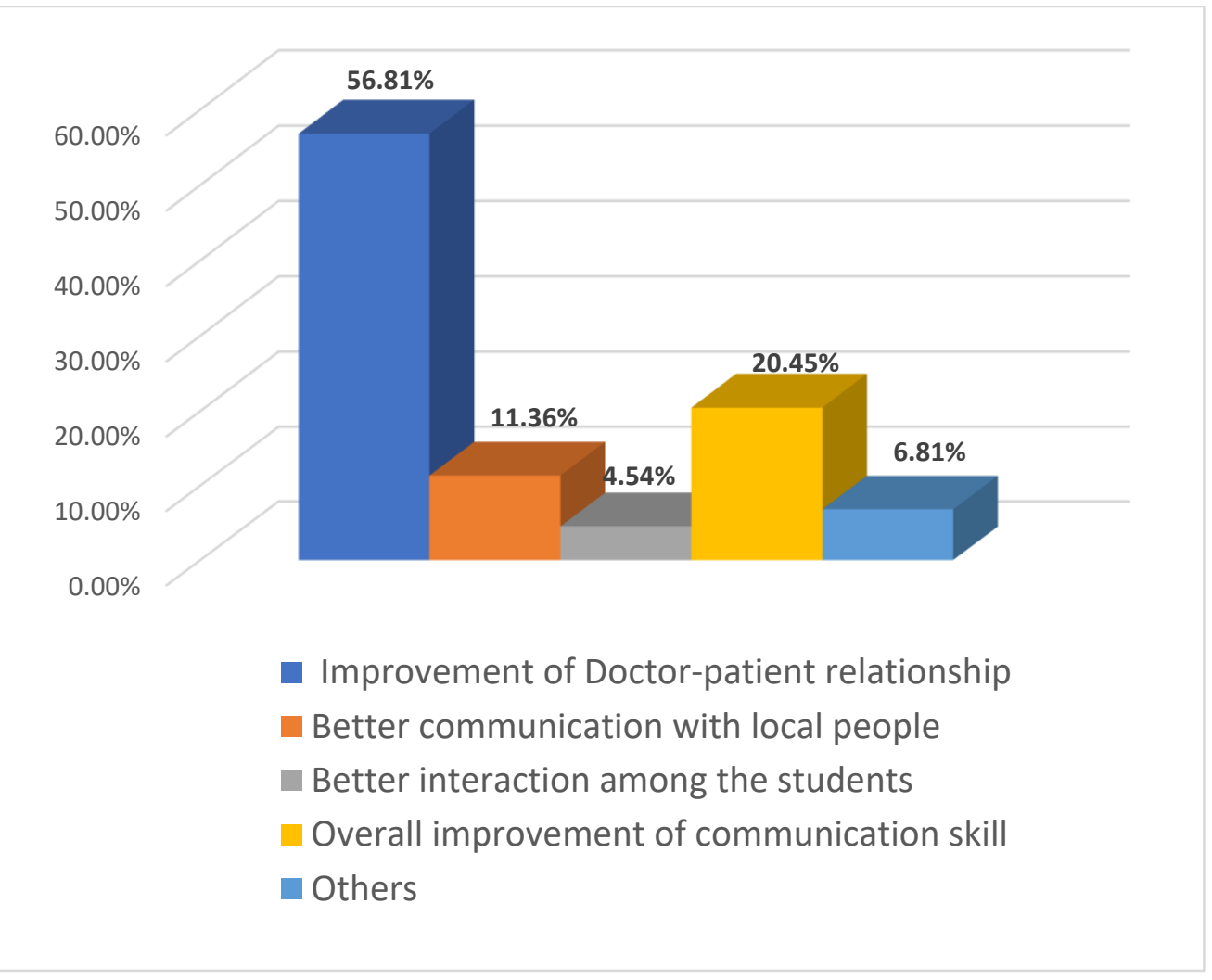




\section{Questionnaire For Students \\ NEET rank....}

\section{Age...}

Sex....

Place of residence...

\section{Languages...}

(Give your opinion according to the 6-point Likert scale which reads:

Very strongly Disagree 1

Agree 4

Strongly Disagree $2 \quad$ Strongly agree 5

Disagree $3 \quad$ Very strongly agree 6)

1. Do you understand local language, Bengali ?(yes/no)

2. Can you freely communicate(talk) with people in Bengali?(yes/no)

3. Will you be able to introduce yourself to a patient in Bengali? (yes/no/may be)

4. Will you be able to ask the patient his/her name in Bengali? (yes/no/may be)

5. Will you be able to ask the patient his/her problem in Bengali? (yes/no/may be)

6. Will you be able to understand the patient's problem in Bengali ? (yes/no/may be)

7. Do you understand Hindi ?(yes/no)

8. Can you freely communicate(talk) with people in Hindi?(yes/no)

9. Will you be able to introduce yourself to a patient in Hindi? (yes/no/may be)

10. Will you be able to ask the patient his/her name in Hindi? (yes/no/may be)

11. Will you be able to ask the patient his/her problem in Hindi? (yes/no/may be)

12. Will you be able to understand the patient's problem in Hindi? (yes/no/may be)

13. Will you be able to communicate with your fellow students from different part of the country in_Hindi? (yes/no/may be) 